\title{
Research on the Development of Energy Conservation and Environmental Protection Industry in China
}

\author{
Yanfang Zhang \\ Department of Basic Education \\ Beijing University of Agriculture \\ Beijing 102206
}

\author{
Yuci Wang \\ Department of Basic Education \\ Beijing University of Agriculture \\ Beijing 102206
}

\begin{abstract}
In recent years, China has placed more emphas is on environmental issues. The energy conservation and environmental protection industry is growing relatively fast, forming a certain scale of benefits. However, there are still gaps in the development of this industry in various regions of the country. This paper uses SPSS statistical software to analyze the statistical data from 2006 to 2015, studies the development of energy conservation and environmental protection industry in China and the influences on it. And it makes factor analysis of raw data, extracts main factors, and calculates factor scores and composite scores of all provinces and cities. The development of environmental protection industries in all regions is ranked in this paper. The results showed that the development were on the decrease from the east to the middle and the western regions, that is, the development of the environmental protection industry in the eastern coast and developed regions was better.
\end{abstract}

Keywords-Energy conservation and environmental protection industry; SPSS statistical software; Factor Analysis

\section{RESEARCH BACKGROUND}

Energy conservation and environmental protection industry refers to the industry that saves energy resources, develops circular economy, and provides technology base and equipment support for environmental protection ${ }^{[1]}$. With the economic development, our country is confronted with increasingly serious environmental problems and increasing demand for governance. As a result, the government has gradually stressed on the development of the environmental protection industry.

In 2010, the State Council promulgated the "On the Decision to Accelerate the Cultivation and Development of Strategic Emerging Industries”, and cultivated and developed the environmental protection industry as one of the strategic emerging industries. During the " 12 th Five-Year Plan" period, the output value of China's environmental protection industry was about 4.5 trillion yuan, and the number of employees in the industry reached more than 30 million. During the "13th Five-Year Plan" period, the annual growth rate of the industry will exceed $20 \%$, and total social investment is expected to reach 17 trillion yuan, accounting for $3 \%$ of GDP ${ }^{[2]}$.

As an emerging industry, the energy-saving and environmental protection industry has developed late and for a short time. There are a few domestic researches on the industry, mainly after 2000. And most of the studies focused on the status quo of the industry and its development obstacles and development prospects ${ }^{[3]}$. The relevant literature available is classified into two categories: research on environmental protection investment and environmental protection industry. Zhu Jingran and He Lingyun ${ }^{[4,5]}$ studied the impact of comprehensive benefits of environmental protection investment in China on the development of the environmental protection industry; Tao Jin ${ }^{[6]}$ studied in detail the influencing factors of China's environmental protection industry in 2015, taking Anhui Province as an example for analysis. Similar to Tao's method, the factor analysis was adopted to reanalyze the influencing factors of China's energy conservation and environmental protection industry, and further ranks the development of environmental protection industries in various regions.

\section{MATHEMATICAL MODEL AND ANALYSIS}

\section{A. Materials and Methods}

1) Data sources and variables setting

The data of this study mainly comes from the statistical yearbook of the official website of the National Bureau of Statistics of the People's Republic of China. The average of data from 2006 to 2015 from all provinces and cities is adopted as the independent variable $(X)$. The variables are set as follows: $x_{1}$ : gross regional domestic product; $x_{2}$ :secondary industry added value (100 million Yuan) contribution rate; $x_{3}$ :tertiary industry added value (100 million Yuan) contribution rate; $x_{4}$ :total energy consumption; $x_{5}$ : energy consumption per unit of gross regional domestic product; $x_{6}$ : sulfur dioxide emissions; $x_{7}$ : nitrogen oxide emissions; $x_{8}$ : volume of soot(dust) emission; $x_{9}$ : bio-chemical waste clearance; $x_{10}$ : quantity of garbage innocuity disposal; $x_{11}$ : R\&D staff of industrial enterprises above designated size; $x_{12}$ : R\&D funds for industrial enterprises above designated size; $x_{13}$ : patent applications for industrial enterprises above designated size; $x_{14}$ : trading of technology market.

\section{2) Introduction of factor analysis [7]}

Factor analysis displays the relationship between the original variable and the main factor by finding common factors of many variables and replacing the original variable with a few "main factors". The mathematical model is: 


$$
\left\{\begin{array}{l}
x_{1}=a_{11} F_{1}+a_{12} F_{2}+\cdots+a_{1 m} F_{m}+a_{1} \varepsilon_{1} \\
x_{2}=a_{21} F_{1}+a_{22} F_{2}+\cdots+a_{2 m} F_{m}+a_{2} \varepsilon_{12} \\
\cdots \cdots \\
x_{p}=a_{p 1} F_{1}+a_{p 2} F_{2}+\cdots+a_{p m} F_{m}+a_{p} \varepsilon_{p}
\end{array}\right.
$$

Factor analysis breaks each variable into two parts: common factor like $F_{1}, F_{2}, \cdots, F_{m}$ refers to the factor that exits in all variables. The unique factor $\varepsilon_{i}(i=1,2, \cdots, p)$ that indicates the impact $\operatorname{on}_{X_{i}}(i=1,2, \cdots, p)$, refers to the part where the original variable cannot be explained by the common factor variable. $a_{i j}(i=1,2, \cdots, p ; j=1,2, \cdots, m)$ is called factor loading, which is the load (or weight) of the $i$ variable on the $j$ main factor, and reflects the relative importance of the $i$ variable on the $j$ main factor.

The KMO test and the Bartlett's test are needed to determine whether the original variable is suitable for factor analysis. The KMO test is used to test whether the partial correlation between the original variables is small enough. The value of $\mathrm{KMO}$ is a relative index of the sum of squares of the simple correlation coefficient and the partial correlation coefficient. The closer it is to 1 , the more suitable it is for factor analysis.

When extracting the main factor, it first extracts the main factor with the largest eigenvalue, and finally extracts the main factor with the smallest eigenvalue, and the cumulative variance contribution rate of the main factor should reach at least $85 \%$. User can specify the number of main factors, or let the software automatically extract factors with eigenvalues greater than one.

\section{B. Data analysis and results}

\section{1) National statistical data factor analysis}

\section{a) Analysis model establishment}

The first step is to determine whether the variable is suitable for factor analysis. The KMO value obtained after processing 14 variables using spss data processing system is 0.815 , indicating that the correlation between variables can be explained by other variables and is suitable for factor analysis.

TABLE I.

EigenVAlue, VARIANCE CONTRIBUtion RATE, VARIANCE ACCUMUlated CONTRIBUtion RATE

\begin{tabular}{|c|c|c|c|c|c|c|c|c|c|c|}
\hline \multicolumn{11}{|c|}{ Total Variance Explained } \\
\hline \multirow[t]{2}{*}{ Component } & & \multicolumn{9}{|c|}{ Extraction Sums of Squared } \\
\hline & & Total & \% of Variance & Cumulative \% & Total & $\begin{array}{l}\% \text { of } \\
\text { Variance }\end{array}$ & Cumulative & \% Total & $\begin{array}{l}\% \text { of } \\
\text { Variance }\end{array}$ & Cumulative \% \\
\hline \multirow{14}{*}{ Dimension0 } & 1 & 8.860 & 63.285 & 63.285 & 8.860 & 63.285 & 63.285 & 7.398 & 52.844 & 52.844 \\
\hline & 2 & 3.031 & 21.648 & 84.934 & 3.031 & 21.648 & 84.934 & 4.134 & 29.530 & 82.374 \\
\hline & 3 & .882 & 6.297 & 91.231 & .882 & 6.297 & 91.231 & 1.240 & 8.856 & 91.231 \\
\hline & 4 & .578 & 4.127 & 95.357 & & & & & & \\
\hline & 5 & .230 & 1.642 & 97.000 & & & & & & \\
\hline & 6 & .182 & 1.297 & 98.297 & & & & & & \\
\hline & 7 & .128 & .912 & 99.208 & & & & & & \\
\hline & 8 & .048 & .346 & 99.555 & & & & & & \\
\hline & 9 & .025 & .175 & 99.730 & & & & & & \\
\hline & 10 & .016 & .118 & 99.848 & & & & & & \\
\hline & 11 & .010 & .070 & 99.918 & & & & & & \\
\hline & 12 & .007 & .049 & 99.967 & & & & & & \\
\hline & 13 & .004 & .030 & 99.997 & & & & & & \\
\hline & 14 & \multicolumn{2}{|c|}{.000} & 100. & & & & & & \\
\hline
\end{tabular}

Extraction Method: Principal Component Analysis.

After the normalization of original data, the correlation coefficient matrix $\mathrm{R}$ of the variables is established. The eigenvalues of $\mathrm{R}$, the variance contribution rate, and the cumulative contribution rate of variance are calculated. From chart 1 , we can see that the amount of information of the selected three main factors is $91.231 \%$, which can reflect the total amount of information of $91.231 \%$, meeting the requirement of being more than $85 \%$ in factor analysis. Therefore, we can take the first three main factor to do factor analysis.

In order to more intuitively reflect the relationship between factors, the factor load matrix is rotated by the variance maximum method, producing chart 2 . As variable 1, 2, 3, 5, 9, $10,11,12$ and 13 possess relatively high loads on the first factor, the first factor mainly explains these 8 variables. The first factor is set as the basic factor $F_{1}$ (economic base, industrial structure, energy consumption level, environmental improvement factors and conditions), which represents the gross regional domestic product, secondary industry added value (100 million yuan) contribution rate, tertiary industry added value (100 million yuan) contribution rate, bio-chemical waste clearance, quantity of garbage innocuity disposal, R\&D staff of industrial enterprises above designated size, $R \& D$ funds of industrial enterprises above designated size, and patent applications for industrial enterprises above designated size. Variable 4, 6, 7 and 8 have relatively high loads on the second factor which is set as pressure factor $F_{2}$ (total energy consumption and environmental pollution emissions in various regions), representing total energy consumption, sulfur dioxide emissions, nitrogen oxide emissions and volume of soot(dust) emission. Variable 14 has relatively high load on the third factor, so the third factor $F_{3}$ is set as market factor 
(marketization process), representing trading of technology market.

TABLE II. ROT ATED COMPONENT MATRIX

\begin{tabular}{lccc}
\hline & \multicolumn{3}{c}{ Component } \\
\cline { 2 - 4 } & 1 & 2 & 3 \\
\hline x1 Gross Regional Domestic Product & .902 & .398 & .114 \\
x2 Contribution Rate of Secondary Industry & .879 & .452 & .000 \\
x3 Contribution Rate of Tertiary Industry & .917 & .264 & .272 \\
x4 Total Energy Consumption & .386 & .906 & -.017 \\
x5 Energy Consumption per Unit of Gross & -.576 & .221 & -.394 \\
Regional Domestic Product & & & \\
x6 Sulfur Dioxide Emissions & .210 & .913 & -.125 \\
x7 Nitrogen Oxide Emissions & .368 & .902 & -.084 \\
x8 Volume of Soot(Dust) Emission & -.054 & .947 & -.068 \\
x9 Biochemical Waste Clearance & .863 & .318 & .180 \\
x10 Quantity of Garbage Innocuity Disposal & .916 & .283 & .210 \\
x11 R\&D Staff of Industrial Enterprises above & .974 & .170 & -.005 \\
Designated Size & & & \\
x12 R\&D Funds of Industrial Enterprises above & .943 & .229 & .048 \\
Designated Size & & & \\
x13 Patent Applications of Industrial Enterprises & .929 & -.059 & -.014 \\
above Designated Size & & & \\
x14 Trading of Technology Market & .153 & -.155 & .944 \\
\hline
\end{tabular}

Extraction Method:Principal Component Analysis.

Rotation Method: Varimax with Kaiser Normalization.

Rotation converged in 5 iterations.

\section{b) Main factor score function}

The spss software is used to calculate the factor score according to the regression algorithm (chart 3 ) to clarify the relationship between the main factor and each variable. The factor score matrix gives the following factor score function (Equation(1)):

$F_{1}=0.112 x_{1}+0.123 x_{2}+0.101 x_{3}-0.044 x_{4}-0.072 x_{5}-0.060 x_{6}$ $-0.033 x_{7}-0.134 x_{8}+0.101 x_{9}+0.111 x_{10}+0.185 x_{11}+0.159 x_{12}$ $+0.210 x_{13}-0.412 x_{14}$

$$
\begin{aligned}
& F_{2}=0.028 x_{1}+0.028 x_{2}+0.010 x_{3}+0.251 x_{4}-0.083 x_{5}-0.258 \\
& x_{6}+0.239 x_{7}+0.318 x_{8}+0.019 x_{9}+0.005 x_{10}-0.083 x_{11}-0.048 \\
& x_{12}-0.156 x_{13}+0.106 x_{14} \\
& F_{3}=0.005 x_{1}-0.097 x_{2}+0.137 x_{3}+0.075 x_{4}-0.240 x_{5}+0.004 \\
& x_{6}-0.010 x_{7}+0.123 x_{8}+0.065 x_{9}+0.077 x_{10}-0.176 x_{11}-0.104 \\
& x_{12}-0.220 x_{13}+0.902 x_{14}
\end{aligned}
$$

TABLE III. COMPONENT SCORE COEFFICIENT MATRIX

\begin{tabular}{lccc}
\hline & \multicolumn{3}{c}{ Component } \\
\cline { 2 - 4 } & 1 & 2 & 3 \\
\hline x1 Gross Regional Domestic Product & .112 & .028 & .005 \\
x2 Contribution Rate of Secondary Industry & .123 & .028 & -.097 \\
x3 Contribution Rate of Tertiary Industry & .101 & .010 & .137 \\
\hline x4 Total Energy Consumption & -.044 & .251 & .075 \\
x5 Energy Consumption per Unit of GDP & -.072 & .083 & -.240 \\
x6 Sulfur Dioxide Emissions & -.060 & .258 & .004 \\
x7 Nitrogen Oxide Emissions & -.033 & .239 & .010 \\
x8 Volume of Soot(Dust) Emission & -.134 & .318 & .123 \\
x9 Biochemical Waste Clearance & .101 & .019 & .065 \\
x10 Quantity of Garbage Innocuity Disposal & .111 & .005 & .077 \\
x11 R\&D Staff of Industrial Enterprises above Designated Size & .185 & -.083 & -.176 \\
x12 R\&D Funds of Industrial Enterprises above Designated Size & .159 & -.048 & -.104 \\
x13 Patent Applications of Industrial Enterprises above Designated Size & .210 & -.156 & -.220 \\
\hline
\end{tabular}




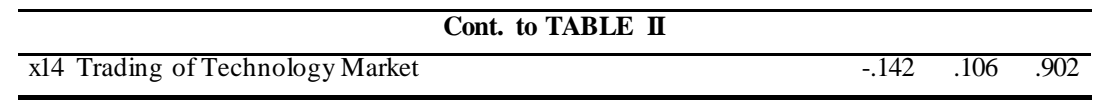

Extraction Method:Principal Component Analysis.

Rotation Method: Varimax with Kaiser Normalization.

Component Scores.

2) Analysis of factor scores and score ranks of all provinces and cities

Based on the results of the provincial and municipal factor scores (chart 4) and the variance contribution rate (chart 1), the composite score calculation formula is (equation (2)):

$$
\mathrm{ZH}=63.285 F_{1}+21.648 F_{2}+6.297 F_{3}
$$

From the composite scoring formula, it can be seen that the basic factor coefficient is 63.285, which has the greatest impact on environmental protection and is three times the stress factor of the second factor. It can be seen that the importance of economic base, industrial structure, energy consumption level, environmental improvement factors and conditions (basic factors) are far greater than total energy consumption, sulfur dioxide emissions, nitrogen oxide emissions, and smoke and dust emissions (pressure factor). In a word, the economic base and industrial structure play the decisive role, and even more significant than the treatment of environmental pollution.

TABLE IV. FACTOR SCORE AND COMPOSITE SCORE RANKS OF ALL PROVINCES AND CITIES

\begin{tabular}{|c|c|c|c|c|c|c|}
\hline \multirow[b]{3}{*}{ Area } & \multicolumn{3}{|c|}{ Factor Score } & \multirow{3}{*}{$\begin{array}{l}\text { Composite } \\
\text { score(ZH) }\end{array}$} & \multirow{3}{*}{$\begin{array}{l}\text { Score } \\
\text { Ranks }\end{array}$} & \multirow[b]{3}{*}{ Category } \\
\hline & F1 & F2 & F3 & & & \\
\hline & $\begin{array}{c}\text { Variance } \\
\text { Contribution Rate } \\
63.285\end{array}$ & $\begin{array}{c}\text { Variance } \\
\text { Contribution Rate } \\
21.648\end{array}$ & $\begin{array}{c}\text { Variance } \\
\text { Contribution Rate } \\
6.297\end{array}$ & & & \\
\hline Guangdong & 3.33863 & -0.14023 & -0.2107 & 206.9227 & 1 & \multirow{4}{*}{1} \\
\hline Jiangsu & 2.60983 & 0.32275 & -0.38682 & 169.7142 & 2 & \\
\hline Shandong & 1.09014 & 2.17041 & 0.29711 & 117.8454 & 3 & \\
\hline Zhejiang & 1.84995 & -0.60441 & -0.70803 & 99.53135 & 4 & \\
\hline Henan & 0.18864 & 1.32769 & -0.05506 & 40.3332 & 5 & \multirow{4}{*}{2} \\
\hline Liaoning & -0.05983 & 1.07724 & 0.36343 & 21.82227 & 6 & \\
\hline Shanghai & 0.52041 & -0.89728 & 0.90162 & 19.18733 & 7 & \\
\hline Hebei & -0.52208 & 2.34339 & 0.19172 & 18.89713 & 8 & \\
\hline Hubei & 0.15678 & -0.11404 & 0.29368 & 9.302387 & 9 & \multirow{4}{*}{3} \\
\hline Sichuan & 0.11049 & 0.05005 & -0.02963 & 7.889262 & 10 & \\
\hline Hunan & 0.14506 & -0.17129 & -0.17936 & 4.342606 & 11 & \\
\hline Fujian & 0.3132 & -0.73359 & -0.27834 & 2.187399 & 12 & \\
\hline Anhui & 0.07096 & -0.16369 & -0.2334 & -0.52258 & 13 & \multirow{2}{*}{4} \\
\hline Beijing & -0.24155 & -0.79708 & 4.92067 & -1.55622 & 14 & \\
\hline Heilongjiang & -0.37172 & 0.17441 & 0.14752 & -18.8197 & 15 & \multirow{17}{*}{5} \\
\hline Shaanxi & -0.45837 & 0.28002 & 0.51353 & -19.7124 & 16 & \\
\hline Inner Mongoolia & -0.8454 & 1.59564 & -0.13045 & -19.7802 & 17 & \\
\hline Tianjin & -0.00281 & -1.09823 & 0.0022 & -23.9385 & 18 & \\
\hline Shanxi & -1.02535 & 1.89112 & -0.14368 & -24.8551 & 19 & \\
\hline Jiangxi & -0.32197 & -0.38243 & -0.10591 & -29.3216 & 20 & \\
\hline Chongqing & -0.20651 & -0.67425 & -0.26936 & -29.3613 & 21 & \\
\hline Jilin & -0.36795 & -0.36286 & -0.17397 & -32.2364 & 22 & \\
\hline Guangxi & -0.36976 & -0.39504 & -0.21338 & -33.2957 & 23 & \\
\hline Yunnan & -0.5231 & -0.27691 & -0.2432 & -40.6304 & 24 & \\
\hline Xinjiang & -0.80855 & 0.32359 & -0.31276 & -46.1335 & 25 & \\
\hline Guizhou & -0.79252 & 0.1335 & -0.69903 & -51.6664 & 26 & \\
\hline Gansu & -0.67361 & -0.45746 & -0.39231 & -55.0029 & 27 & \\
\hline Hainan & -0.47206 & -1.46716 & -0.30275 & -63.5418 & 28 & \\
\hline Xizang & -0.60012 & -1.50864 & -0.51528 & -73.8824 & 29 & \\
\hline Ningxia & -0.92422 & -0.46969 & -1.14793 & -75.8856 & 30 & \\
\hline Qinghai & -0.80661 & -0.97553 & -0.90013 & -77.8327 & 31 & \\
\hline
\end{tabular}


The higher the score is, the better the development of the environmental protection industry is. From the chart 4, we can conclude that Guangdong has the highest score, followed by Jiangsu, Shandong and Zhejiang provinces. The scores of Guangdong Province and Qinghai Province differ by about 283. What's more, the scores show a decreasing trend from the southeast and the east to the west with huge gaps. According to the composite scores, the provinces and cities are classified into five categories (clusters). The classification is not based on equidistant division, but the magnitude of the numerical value. Those have small gap between them are in one category. The northeastern provinces all belong to category 5, except Liaoning province which is in the second category. Therefore, the overall environmental protection level is poor. Most cities in western region belong to the category 5 . Sichuan province belongs to category 3 , and has a good environmental protection industry, much better than Chongqing. Among municipalities, Tianjin and Chongqing also belong to category 5, and Shanghai is far ahead of the rest, belonging to category 2 . The composite scores of the four municipalities vary greatly.

\section{CONCLUSION AND SUGGESTIONS}

\section{A. Conclusion}

Judging from the composite scores of all provinces and cities across the country, we can conclude that the development of energy conservation and environmental protection industries in the eastern coast and developed regions is generally better than those in the western regions. The declining from the east to the middle and the west shows that the overall level of development of the industry in the eastern regions is higher than that in the central regions, and the central regions are better than the western regions. Four provinces, namely Guangdong, Jiangsu, Shandong and Zhejiang are far ahead, while among the central regions, the composite scores of Hubei and Hunan are relatively high. In the municipalities, Shanghai is the best one in the development of the environmental protection industry, and Beijing is at a medium level. Liaoning Province is better. Sichuan has the highest score than any other province in western region, much higher than the neighboring
Chongqing. However, the situation in Hainan Province is rather special and the ranking is low, which needs further analysis and discussion.

\section{B. Policy and suggestions}

The government should make greater effort to strengthen environmental laws and regulations and enhance the environmental awareness of enterprises and people. And it can guide and supervise energy conservation and environmental protection activities to reduce environmental pollution. Strengthen macro management and play its guiding role. Furthermore, the government should encourage the development of advanced energy-saving products and technologies and if necessary, take corresponding subsidy measures or provide financial support. Through the integration of production-study-research, it can cultivate environmental technology talents in real time.

\section{REFERENCES}

[1] Liu Jianqiu,Lan, Guoqian, Guo Lijian, Zhang Jiangwei. Investigation and Analysis on Development of Environmental Protection Industry in Hebei Province[J]. Management \& Technology of SME, 2014,(12):131-133.

[2] http://finance.sina.com.cn/china/20151102/222723655477.shtml

[3] Zhang Qiongzhi. Study on the Influencing Factors of the Growth of China's Energy Conservation and Environmental Protection Listed Companies [D]. Anhui University, 2013.

[4] Zhu Jingran, He Lingyun, Zhu wei. Research on Comprehensive Benefit of China's Environmental Protection Investment Based on Classification [J]. Ecological Economy, 2014,(01):107-114.

[5] He Lingyun, Zhu Jingran, Bian Dance. Research on the Impact of China's Environmental Protection Investment on the Development of Environmental Protection Industry-An Empirical Analysis Based on National and Regional Sample Data [J]. Ruan Kexue,2013,(01):37-41.

[6] Tao Jin. Research on the Influencing Factors of Energy Conservation and Environmental Protection Industry in China[D]. Anhui University of Finance and Economics, 2015.

[7] Tan Rongbo, Mei Xiaoren. SPSS Guide to Data Analysis [M].Beijing: Science Press,2007. 